On July 7, Prof. P. G. Homeyer (Iowa State College) summarized experience on sources of variation in feeding experiments with chicken, cattle and pigs, and its use in designing new experiments; he emphasized particularly the danger of neglecting variation between pens. Dr. G. L. Rocha (Brazil) and Dr. G. O. Mott (Purdue University) reviewed the technique and interpretation of pasture experiments in Brazil and the United States, respectively, after which Prof. A. Linder (University of Geneva) described an experiment on the grazing times of cows permitted to choose between differently treated plots. In the afternoon session, on sampling tech. niques, Dr. M. H. Hansen (United States Bureau of the Census) discussed the control of errors of response in sample surveys. Recent work on the theory and practice of estimating fish catches around the Indian coast was then described by Dr. P. V. Sukhatme (Food and Agriculture Organization). Prof. J. Nieto de Pascual (Bureau of Statistics, Mexico) described a survey of national morbidity in Mexico, and Prof. W. L. Stevens (University of São Paulo) presented an account of recent work on the sample estimation of the coffee harvest, a problem complicated by a biennial cycle of bearing. The session ended with a paper from Dr. E. Cansado (Interamerican Statistical Centre, Santiago, Chile) on new proofs of theorems on sampling from a finite population.

After a morning visit to the State Institute of Agronomy at Campinas, the afternoon of July 8 was given to papers on bioassay. Dr. C. I. Bliss (Connecticut Agricultural Experiment Station) showed general methods for obtaining confidence intervals for estimates of relative potency, and then illustrated how these could be adapted to various assay techniques in the "U.S. Pharmacopeia". Dr. D. J. Finney (University of Aberdeen) presented five models relating to correlations of residual error and residual effects of previous doses in cross-over and singlesubject assays, and explained the statistical analysis appropriate to various designs. Dr. P. Mello Freire (Institute of Biology, São Paulo) described the analysis and interpretation of three 'complement fixation' assays. Finally, several questions on bio-assay, with special reference to the assay of snake venom, were submitted to a panel for discussion.

The first of four papers on medical statistics on July 9 , that by Dr. J. O. Irwin (London School of Hygiene and Tropical Medicine), related to an experiment conducted in Singapore with human subjects to assess the influence of air movement, temperature, humidity, clothing and other factors on sweat-rate and other physiological measurements. An interesting application of covariance analysis was shown by Dr. J. N. Manceau (Public Health Service, Pará) in his account of a comparison between two antihelminthics for the control of nematode parasites in seventy-four Belém children. Dr. A. E. Brandt (United States Atomic Energy Commission) described briefly an investigation into the clinical effects of two different very high-voltage sources proposed for the treatment of cancers that are frequently incurable by conventional radiotherapy; he then considered the problems of performing a clinical trial on one type of cancer, with adequate random allocation of patients to the two treatments yet within the limits imposed by medical ethics. The final paper, by Prof. A. Vessereau (Sorbonne), consisted of an interesting application of discriminant function analysis to the diagnosis of medical and surgical cases of jaundice from electrophoretic analysis of serum proteins.

One of the most satisfactory features of the sym. posium was the lively discussion that followed almost every paper : the variety of questions and comments, and the number of people taking part, proved that the holding of the symposium was fully justified. Moreover, Brazilian science will continue to benefit from this venture, for it provided the impetus for the immediate formation of a Brazilian Region of the Biometric Society (which already has more than fifty members) and also of a Brazilian Genetical Society.

D. J. Finney

\section{DESIGN OF ELECTRONIC DEVICES FOR PRODUCTION}

A SUMMER school on the role of the trained scientist in the design of electronic devices for production was held at the Services Electronics Research Laboratories in Baldock and Harlow during September 20-23. More than sixty university and technical-college professors and lecturers attended. Accommodation was provided by Emmanuel College, Cambridge, and transport to and from the Laboratories was by motor coach.

The first speaker was Mr. A. J. Young (English Electric Valve Co.), who surveyed the recent developments in special valves. $\mathrm{He}$ directed attention particularly to one of the functions of management in the device industry, namely, to decide to pursue a particular line of development. The scientific judgment required to execute this function to the best advantage is an increasing need in the industry, and it should be the object of the universities and technical colleges to bring forward scientists having good understanding of their subject and, as a result, good judgment regarding device development. The next speaker was Mr. D. S. G. Lewis (officer in charge of the extension of the Services Electronics Research Laboratory at Harlow), whose subject was mag. netrons, and he gave a résumé of the problems facing the designer after fifteen years of development. In particular, he directed attention to the complicated nature of the device, in which the variation of any one parameter alters the effect of every other one. Mr. Lewis sketched the problems arising in the manufacture of magnetrons, giving special attention to the close limits imposed at very high frequencies. The final speaker on the first day was Dr. J. M. Dodds (Metropolitan-Vickers Electrical Co., Ltd.), his subject being high-power klystrons. He explained why the klystron is preferred to the magnetron for certain purposes, and described the design and manufacture of a klystron suitable for driving a very high-power linear accelerator. During this first day examples of modern valves were exhibited, many valve firms contributing samples of their latest designs. In the afternoon, Dr. H. A. H. Boot, one of the inventors of the multi-cavity magnetron, supervised a demonstration of micro-wave valve-making techniques.

The second day of the school opened with a discussion of methods of generation of millimetre waves, given by Mr. P. O. Hawkins (Services Electronics Research Laboratory). Mr. Hawkins, in addition to surveying the field, gave special attention to a floating drift tube klystron capable of delivering 10-20 W. at a wave-length of $8 \mathrm{~mm}$. He was followed by $\mathrm{Dr}$. 
R. Q. Twiss (also of the Services Electronics Research Laboratory), who illustrated forward thinking by discussing the prospects of developing and detecting sub-millimetre waves; he gave special attention to the use of electrons travelling at approximately the speed of light. Mr. G. Knott (Mullard Research Laboratories) described the action of travelling-wave amplifiers and of backward-wave oscillators. In the first part of his discourse he referred particularly to the problem of noise in signal amplifiers and to the yet unsolved problems of mechanical design; in the second part he sketched the theory of backwardwave valves and described results achieved at a wave-length of about $2 \mathrm{~cm}$. which may lead to a new generation of low-power micro-wave oscillators.

The school then turned its attention to the important subject of reliability in electronic devices, and on this subject an address was given by $\mathrm{Mr}$. E. G. Rowe (Standard Telephones and Cables, Ltd.). Mr. Rowe explained what steps had been taken since 1945 to improve the general reliability of valves and described the problems which still remained to be solved. He was followed by Mr. G. H. Metson (Research Station of the General Post Office), who dealt specifically with the problem of designing valves for lives of the order of a hundred thousand hours (more than eleven years) and gave a scientific explanation of the factors determining long life in cathodes. In the morning a demonstration was given of millimetre-wave generators, and in the afternoon Mr. P. Gurnell superintended a demonstration of receiving-valve manufacturing techniques. The day closed with a lively discussion of how best to teach at university standard so as to obtain industrial scientists having a real understanding of scientific problems.

On September 22 the school transferred to Harlow, where it was addressed by Dr. D. A. Wright (Research Laboratories of the General Electric Co., Ltd.) and later by Mr. C. P. Lea-Wilson (Harlow) on the subject of thermionic cathodes. Dr. Wright described all types of thermionic emitter, dealing particularly with the limitations of the oxidecoated cathode, while Mr. Lea-Wilson paid special attention to high-temperature sintered cathodes used in magnetrons and high-power klystrons. Mr. J. Pollard (Services Electronics Research Laboratory) then discussed methods of obtaining high vacua and explained that the needs of the valve engineer are not yet adequately met either as regards speed of pumping or as regards ultimate vacua. In the afternoon Mr. J. E. Stanworth (British Thomson-Houston Research Laboratory) described the problems arising in the manufacture of glass and ceramic valve envelopes. In the second part of his address he dealt specifically with some of the new and interesting glasses developed recently. In the evening $\mathrm{Mr}$. A. Monk (Harlow) supervised a demonstration of the use of new materials in valve making.

The final day of the school was devoted to problems arising in connexion with solid-state devices. The introductory discourse was given by Mr. I. M. Ross (Services Electronics Research Laboratory), who surveyed the whole field, giving examples of entirely new solid-state devices which have come to light during the past few years. He was followed by Mr. E. H. Cooke-Yarborough (Atomic Energy Research Establishment), who described the properties of transistors and some of the uses to which they are being put. He emphasized that the transistor is a new type of electronic device in many ways utterly dissimilar to a valve and demonstrated some of the surprising circuits in which transistors can be used. Mr. E. B. Callick (Royal Naval Scientific Service) then discussed the problems encountered in manu. facturing transistors and emphasized that these represent an entirely new development in manufac. turing methods, where extremely minute traces of impurity are of primary importance and where the physical magnitudes involved are very small indeed. In the afternoon Mr. A. F. H. Thomson (Harlow) described the various types of memory or storage devices which are coming into use, taking the view that magnetic materials will play an ever-increasing part in this field. He was followed by Mr. P. E. Trier (Mullard Research Laboratories), who dealt, more specifically with magnetic switching devices. He showed how these can be built up into a full-scale computer and gave special attention to the difficult scientific problems which have yet to be solved in connexion with the use of ferro-magnetic materials and ferrites. During the afternoon a demonstration was given of solid-state devices in use in various ways.

In the short time which remained for discussion it was suggested that the proceedings of the school should be made available, at least in an abridged form, and it is hoped to publish these in the Journal of Electronics early next year.

J. THOMSON

\section{ANIMAL MOVEMENT}

$\mathrm{D}$

URING the British Association meeting at Bristol, Sections D (Zoology) and I (Physiology) held a joint session on September 6, at which the subject of "Animal Movement" was discussed. The first paper was by M. A. Sleigh, speaking on ciliary movement, and in it he gave an account of his own work on the movement of the peristomial cilia of Stentor. He suggested that the frequency of beat is a measure of the mechanical activity and that wave velocity is a measure of the metachronal co-ordination. Experiments have shown that the beat frequency and wave velocity have different temperature coefficients. Also it can be demonstrated that changes in the viscosity of the medium and in the viscosity of the protoplasm affect only the frequency and not the wave velocity, while the wave velocity can be substantially altered by digitoxin without appreciably affecting the frequency. The conclusion to be drawn is therefore that the two parts of the system are separate and have very different properties. Mr. Sleigh holds the view that the frequency might be maintained by the first cilium in a row acting as a pace-maker, while the excitation pathway of the wave velocity might be neuroid.

The second paper, by Dr. T. Weis-Fogh, was on the flapping flight of insects, and was illustrated by a slow-motion film on the flight of the desert locust. He described the wing movements in detail, and explained how the film was made and how his co-worker, Dr. Martin Jensen, had used it for estimating the changes both in magnitude and direction of the aerodynamic forces during the beat cycle. It has become clear that the wing cycle can be treated as a series of stationary flow situations and that the torques set up at the wing base can be estimated. When these torques are considered in detail, it is possible to subdivide them into aerodynamic and inertial torques, and to relate them to the torqueproducing components within the body. From this 